\title{
Ovarian cyst seen on plain abdominal radiograph
}

\author{
Monika Rezacova* \\ General Surgery ST3, Queen Alexandra Hospital, Portsmouth, UK
}

\begin{abstract}
I report an unusual case of middle age female with sudden onset of lower abdominal pain. This was not associated with any other symptoms however patient had one large bowel motion earlier that day. The plain abdominal radiograph showed lesion within pelvis suspicious of ovarian cyst/teratoma which has large potential of torsion. This was later confirmed during laparoscopy. Patient has made uneventful recovery.
\end{abstract}

\section{Case report}

A 41-years old female has been referred for general surgical review while attending emergency department with lower abdominal pain. The patient was usually fit and healthy, non-smoker with no regular prescription medication. She used regular out of counter laxatives since being a kid for constipation.

Patient presented to emergency department with sudden onset of lower abdominal pain which was intermittent and colicky in nature. The pain was severe and lasted for 4 hours when she presented to emergency department. There was minimal help with the pain from analgesia including morphine in department. There were no associated gastrointestinal symptoms including nausea, vomiting or diarrhoea however patient had one episode of large bowel motion earlier that day. Patient had Mirena coil in place which did not caused her any complication since insertion. Her last period was prior to first Mirena coil insertion 6 years ago. Patient denied any bleeding or unusual discharge or any other gynaecological symptoms. There was no family history of bowel disease.

On examination the patient was in a lot of pain in suprapubic area and left iliac fossa with some voluntary guarding however no rebound was elicit during abdominal examination. The pain did not radiate anywhere and was of severity 10/10 despite strong analgesia. Bowel sounds have been quiet and there was no pathology found on per rectum examination.

The bloods showed only very mild inflammatory response of white cell count of 12.5 , no other laboratory abnormalities have been detected at the time of presentation.

Due to the nature of pain and inconclusive blood results, patient underwent plain abdominal radiograph. This showed $4.3 \times 2.6 \mathrm{~cm}$ calcified lesion in the pelvic region forming teeth-like shape. This appearance was consistent with ovarian cyst/teratoma pathology which has large potential of torsion. (Figures 1 and 2)

\section{Treatment and follow up}

Patient was referred urgently to gynaecology team and the findings have been confirmed on trans-vaginal ultrasound and intra-operatively. Patient underwent laparoscopy + cystectomy as the torte ovary was deemed viable following untwisting intraoperatively.

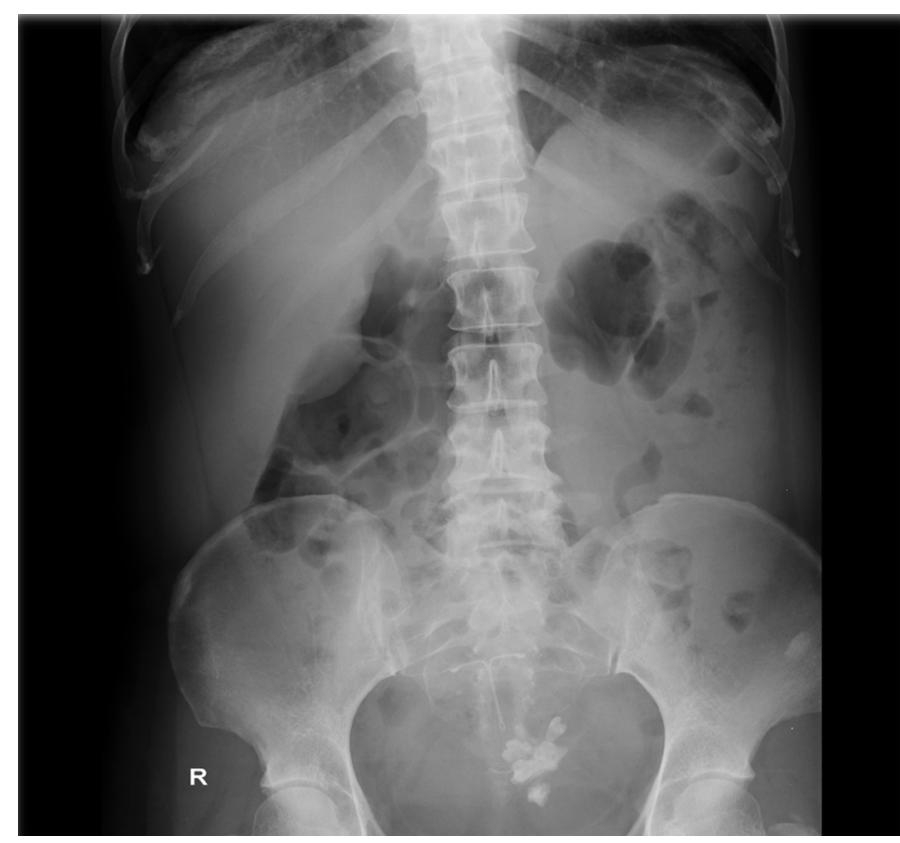

Figure 1. Ovarian cyst on plain abdominal radiograph - see teeth forming structure in left side of the pelvis

Patient made full recovery and was discharged home next day. Histopathology report 2 weeks post operatively has confirmed a dermoid cyst containing skin, hair, bone and smooth muscle.

\section{Discussion}

I present this case to demonstrate how simple imaging can change management of the patient. There were very inconclusive presentation and blood results for any surgical diagnosis. Diagnosis of ovarian pathology on plain abdominal radiograph in acute setting is rare and is usually picked up as accidental finding on imaging for other purposes.

Correspondence to: Monika Rezacova, MRCS, General Surgery ST3, Queen Alexandra Hospital, Portsmouth, UK, Email: rezacovamonika@doctors.org.uk

Received: February 03, 2018; Accepted: February 26, 2018; Published: March 01,2018 


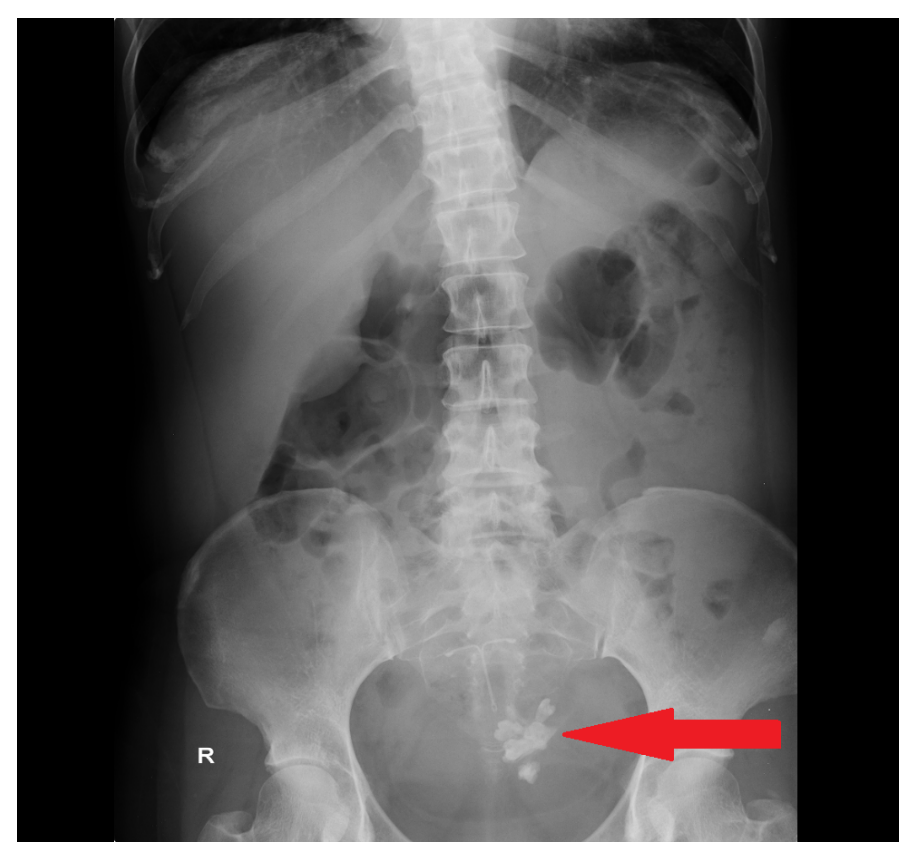

Figure 2. Ovarian cyst on plain abdominal radiograph - see teeth forming structure in left side of the pelvis (red arrow)
In this case, plain radiograph helped the diagnosis and prompt operation which resulted in saving of patient's ovary.

\section{Consent}

Informed consent for the case to be published (including images, case history and data) was obtained from the patient.

Copyright: (C2018 Rezacova M. This is an open-access article distributed under the terms of the Creative Commons Attribution License, which permits unrestricted use, distribution, and reproduction in any medium, provided the original author and source are credited. 